\title{
TEMPERATURE INVERSION MEASUREMENTS IN SARAJEVO VALLEY USING UNMANNED AERIAL VEHICLES
}

\author{
Adnan Mašić, Rajfa Musemić \& Emina Džaferović-Mašić
}
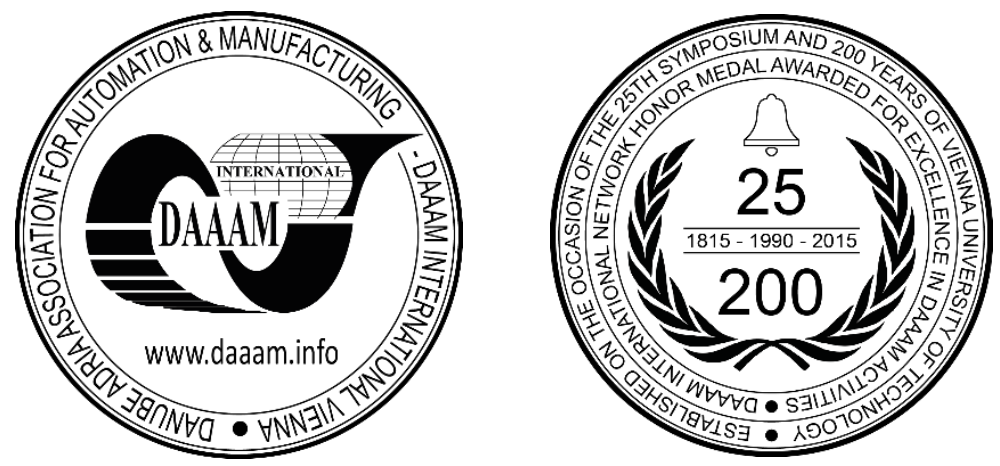

This Publication has to be referred as: Masic, A[dnan]; Musemic, R[ajfa] \& Dzaferovic-Masic, E[mina] (2016). Temperature Inversion Measurements in Sarajevo Valley Using Unmanned Aerial Vehicles, Proceedings of the 27th DAAAM International Symposium, pp.0423-0427, B. Katalinic (Ed.), Published by DAAAM International, ISBN 9783-902734-08-2, ISSN 1726-9679, Vienna, Austria DOI: $10.2507 / 27$ th.daaam.proceedings.062

\begin{abstract}
Temperature inversions represent an important element of air pollution in cities situated in natural valleys, such as the Sarajevo Valley. Due to the strong thermal stratification, which acts as a natural lid over the city, air circulation is blocked and pollutants accumulate and stay for much longer time. As a consequence, air pollution in the residential area of the city increases dramatically. Investigation of the temperature inversions in Sarajevo Valley was, for the first time, performed using unmanned aerial vehicles.
\end{abstract}

Keywords: Temperature inversion; Sarajevo Valley; Unmanned Aerial Vehicles.

\section{Introduction}

Air pollution is becoming a major environmental issue. Cities situated in the natural valleys have particular problem of thermal stratification during the winter [1]. These stratifications sometimes stay for weeks, and during that period concentrations of pollutants rise dramatically. The city of Sarajevo is clear example (Figure 1).

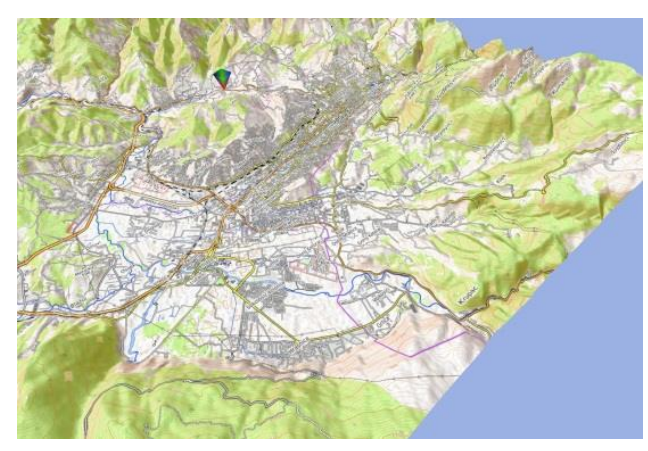

Fig. 1. Sarajevo Valley 
Thermal stratification in the Sarajevo Valley was previously investigated by means of computer simulation and turbulence modelling [2]. The turbulent flow of air was simulated using Large Eddy Simulation with subscale model [3]. However, no experimental studies of the temperature inversion layer in the Sarajevo Valley were reported, up to now.

The purpose of this study is to evaluate the possibility of using unmanned aircrafts equipped with data acquisition systems to investigate the phenomenon of the temperature inversion in the Sarajevo Valley. Accurate temperature profiles are required for any successful modelling (analytical or computer based) of this phenomenon. Our hypothesis is: our custom data acquisition system is suitable for installation on the unmanned aerial vehicle for measurements and modelling of the temperature profiles in the inversion layer.

Unmanned Aerial Vehicles (UAVs), often called "drones" in the mainstream, are increasingly popular nowadays. They are being used for aerial imaging, research and commercial purposes. We have developed a research platform which includes quad-rotor in "X" configuration (Figure 2) and custom made data acquisition system (DAS) [4].

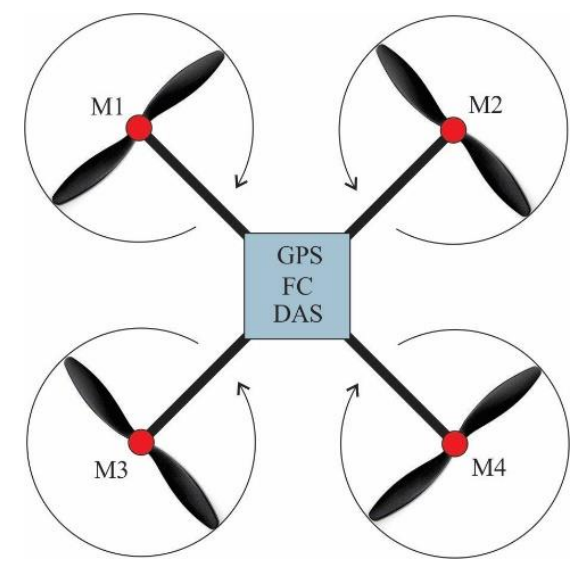

Fig. 2. Schematic view of quadcopter

The flight dynamics [5], [6], [7] and [8] is maintained by different amount of power sent to motors M1 to M4, which is calculated by a computer called flight controller (FC). The hardware of flight controller includes various sensors:

- MPU6050 6-axis gyroscope and accelerometer with Motion Processing Unit

- HMC5883L 3-axis digital magnetometer

- MS5611-01BA03 high precision altimeter

- Ublox NEO-M8N GPS/GLONASS receiver (external).

The CPU of the flight controller, ATMega2560 in our case, monitors all data from the abovementioned sensors, and calculates the required throttle levels for each motor in order to preserve the desired trajectory of the aircraft and to keep it stable in the air. The software in the flight controller can be proprietary (in which case user can only change few adjustable parameters) or open-source. Our UAV is based on an open-source flight controller, which is essential. This enables us to change (when necessary) all flight parameters and routines.

The flight controller uses a PID loop [9], [10] for control of the motors. The stability of PID controller [11] is essential, and the tuning of the propulsion system requires a lot of adjustments which were carefully performed in our laboratories.

Once calculated by the FC, throttle levels are applied to individual motors using the electronic speed controllers (ESC), one for each motor. The ESCs use pulse-width modulation (PWM) [12] to control (brushless) motors.

The flying platform can be controlled manually via radio control unit, or it can fly autonomously (GPS augmented). For this function, extremely capable GPS receiver is necessary. Ublox GPS receiver of the eighth generation uses both GPS and GLONASS satellites. The typical number of acquired satellites is about 20, with HDOP (horizontal dilution of precision) of 2.0 or less.

Battery for aircraft contains lithium-polymer cells, with standard voltage of $3.7 \mathrm{~V}$ (per cell). The modular platform of our UAV allows installation of batteries of various capacities, depending on the desired mission parameters. For example, smaller battery can be used if the payload is heavy, and required time of flight is short enough.

Together with the development of the UAV, we have been working on data acquisition system. For this particular purpose, DAS should have fulfilled the following requirements: 
- small dimensions

- low weight

- low power consumption

- availability of required sensors and software platform.

The microcontroller based on Arduino [13] fitted perfectly. Some aspects of similar microcontrollers are analysed in [14].

\section{Measurements and Results}

After successful tests in the laboratory, we connected DHT22 sensor [15] to our DAS and performed full flights. Digital sensor DHT22 measures temperature and relative humidity, and atmospheric pressure is measured by Bosch BMP085 (digital) sensor [16]. Some measurements were performed using proprietary DAS, Pasco Xplorer. We will present two characteristic measurements here: one during the day without any temperature inversion, and other when the thermal stratification was strong. Location of both measurements is indicated by cursor in Figure 1.

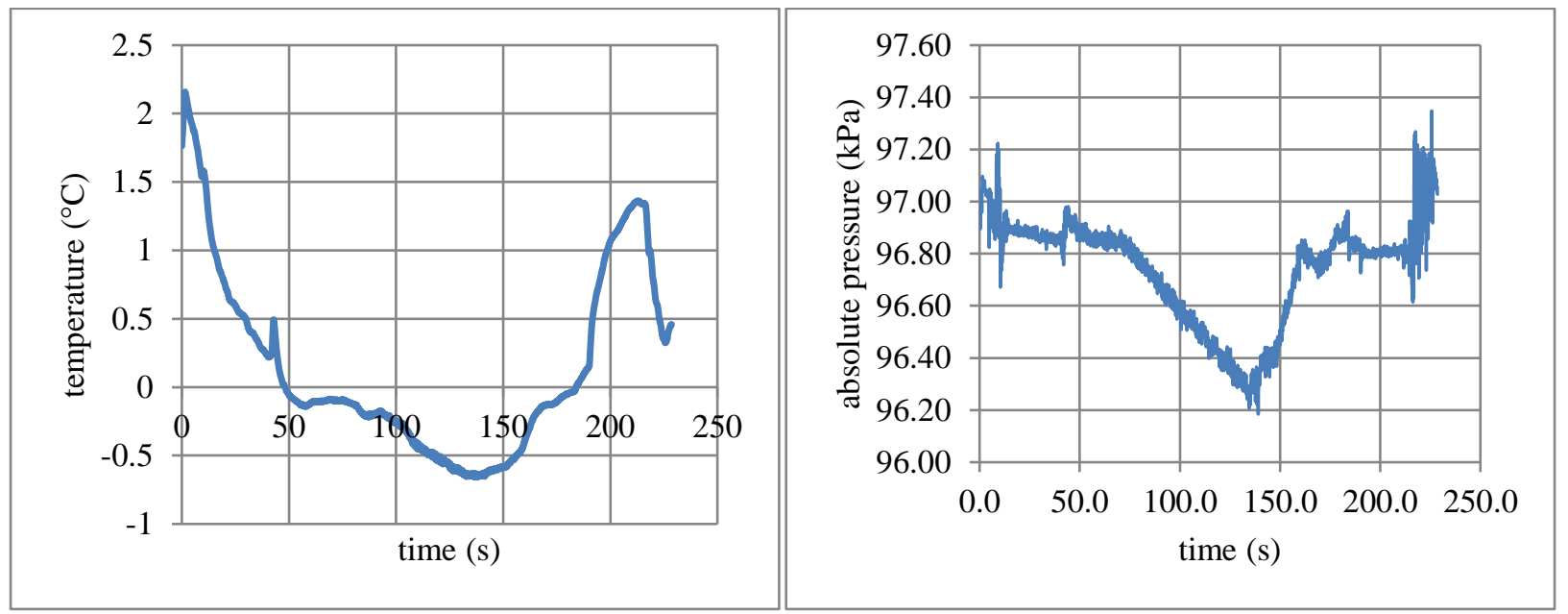

Fig. 4. Pressure and temperature graph during the day without temperature inversions.

Figure 4 shows temperature and pressure readings (Pasco Xplorer DAS was used) during the clear winter day, without temperature inversion. We can see that the temperature decreases with altitude (temperature and pressure measurements are synchronized and pressure indicates the altitude), just as expected. Turbulent nature of air flow (due to propellers) can be seen on the pressure graph. Measurements of the temperature inversions are presented in Figure 5. Sensors DHT22 and BMP085 were used. Altitude above ground was calculated using the barometric pressure readings from BMP085 sensor.
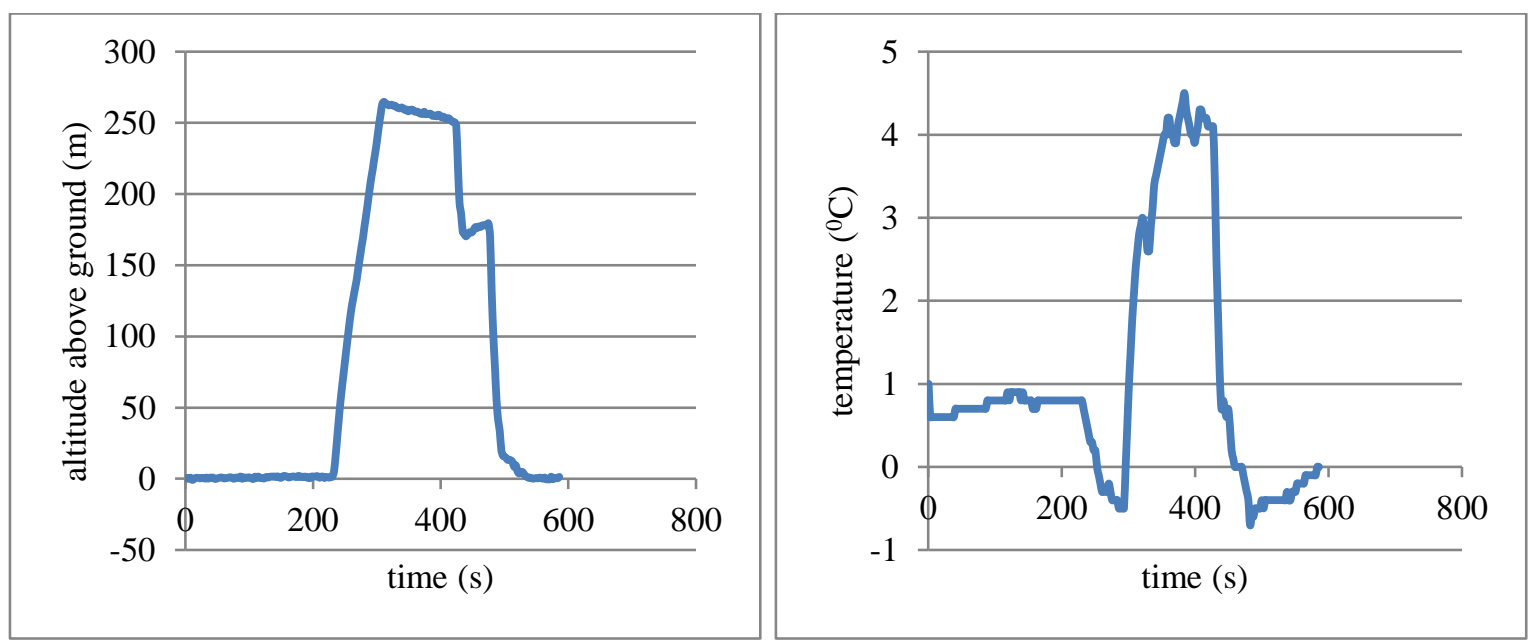

Fig. 5. Measurements of the temperature inversion

The presented graphs have time as independent variable (as they were logged in DAS). It is not difficult to produce temperature-height graphs, by eliminating time. However, due to non-negligible thermal mass of the DHT22 sensor, there is some inertia in the process of measurement of the temperature, which is significant during the fast climbs and descents. This effect produces hysteresis in the temperature-height graph. A convenient way to overcome this problem is to take 
two temperature values for every height, and calculate the average value of these two temperatures. Furthermore, the difference between values of temperature, during ascend and descent, on the same height gives an indication of the uncertainty of the temperature measurement. Figure 6 shows the temperature-height graph using this processing technique, together with uncertainties. Polynomial fit of third order is added as well. The fit is not perfect, but is reasonably good analytical model of the temperature profile in the inversion layer. This means that our hypothesis is fully confirmed.

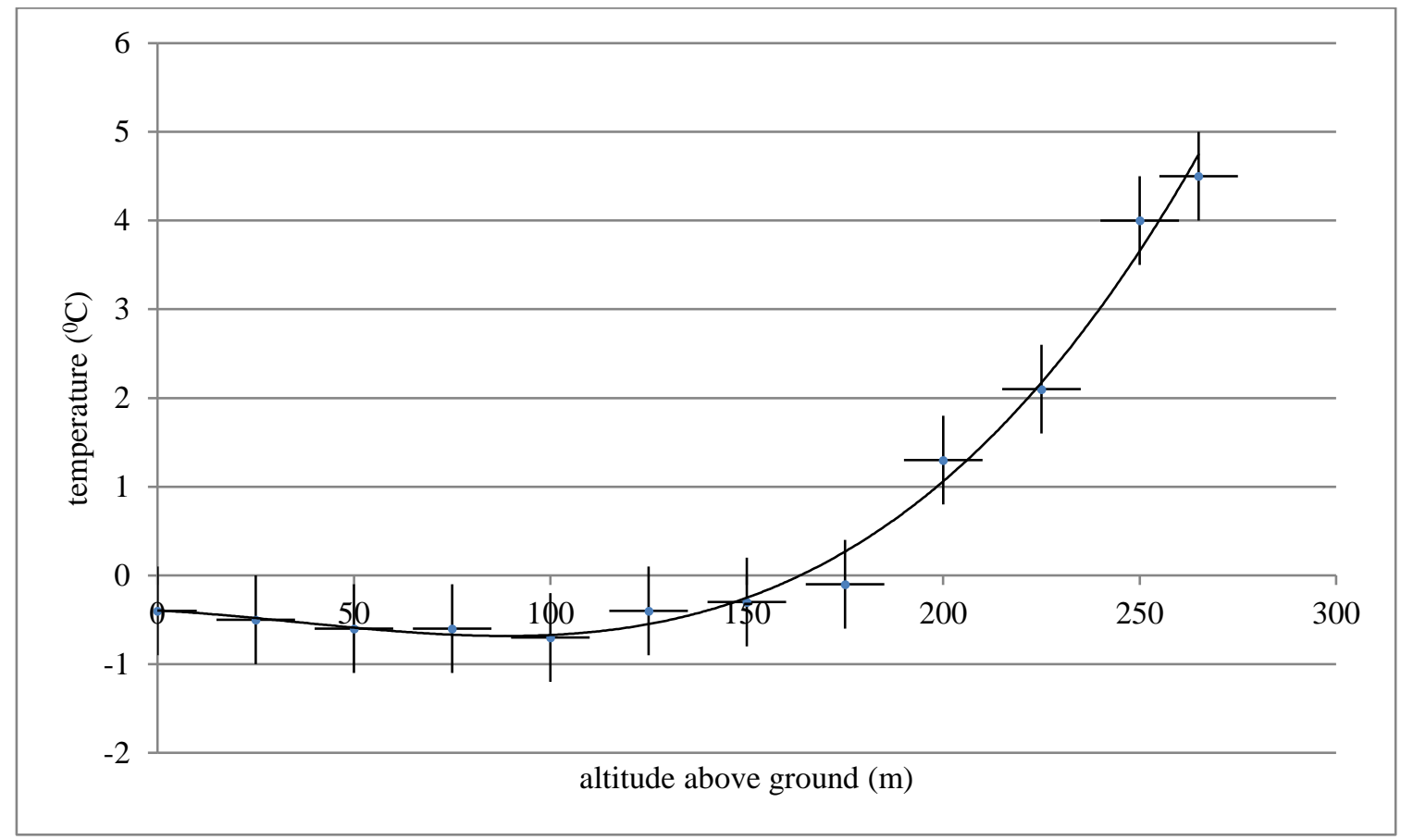

Fig. 6. Temperature-height profile during the day with strong temperature inversion

In the Figure 6 we can see that during the first 100 meters temperature barely changes and even decreases with the altitude. However, from $150 \mathrm{~m}$ to $250 \mathrm{~m}$, temperature rises by about 5 degrees! This is inversion of 1 degree Celsius every 20 meters, which is really strong stratification. Figure 7 illustrates the consequence: nothing can escape this natural lid, and the city is completely covered by huge amount of (dirty) air. Some 250 meters above the city, the inversion layer disappears.

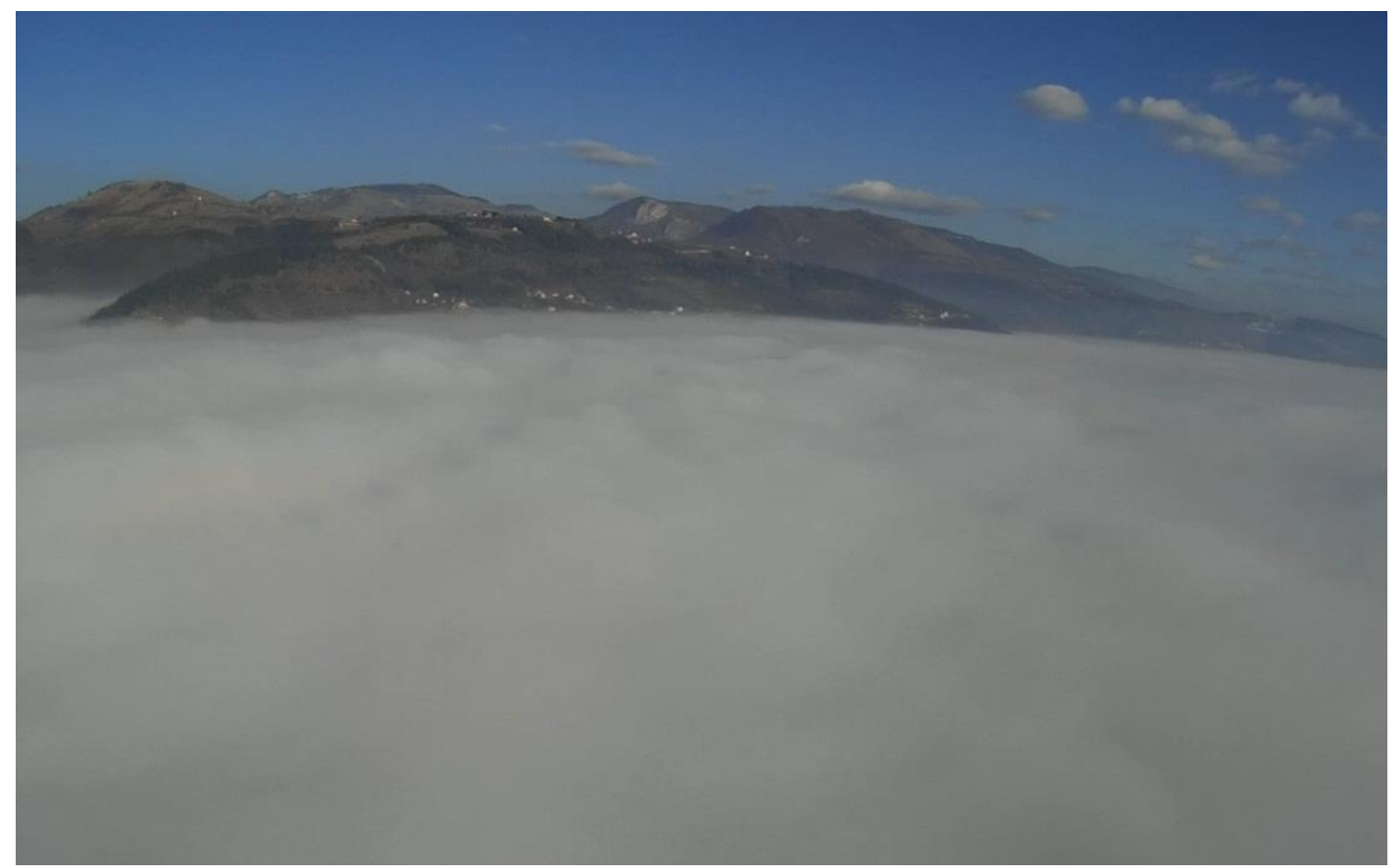

Fig. 7. Pollutants above the city of Sarajevo as a consequence of temperature inversion 


\section{Conclusion}

Unmanned aerial vehicle with data acquisition capabilities was built and used for the investigation of temperature inversions above the city of Sarajevo. Open-source flight controller was used and in-house developed data acquisition system. Temperature, pressure and humidity values were collected. This platform was successfully launched during several clear days and those with strong temperature inversion. Temperature profiles exposed that some inversions were as strong as 1 degree Celsius every 20 meters. Such temperature profiles can be approximated by third order polynomial.

In the future, we plan to build larger UAV with capability to carry more instruments and with longer flight time. Obtained data can be combined with computer simulations, for complete understanding of the phenomenon of temperature inversion and its consequences. Another possibility to expand this research is to use equipment for monitoring of certain air pollutants (such as particulate matter or volatile organic compounds) together with temperature profiles. That could be used as input for computer simulations of multiphase flows, and completely new level of modelling. Environmental strategies should also take this data into considerations. Currently, we act after the air pollution parameters reach critical values. Using this method, we can predict the situation and act before we reach the critical level of air pollution.

\section{Acknowledgments}

This research is supported by a grant of the Government of Sarajevo Canton, Ministry of Education and Science, which is greatly acknowledged.

\section{References}

[1] Kenjereš, S. \& Hanjalić, K. (2002). Combined effects of terrain orography and thermal stratification on pollutant dispersion in a town valley: a T-RANS simulation. Journal of Turbulence, 1468-5248, 3(26): 1-21.

[2] Musemić, R. \& Krstović, G. (2005). Numerical Simulation of Actual Heat Flux Effects on Air Ventilation in the Mountainous Town Valley of the City of Sarajevo. 9th International Research/Expert Conference "Trends in the Development of Machinery and Associated Technology" TMT 2005, Antalya, Turkey, 26-30 September, 2005.

[3] Musemić, R. \& Krstović, G. (2006). Numerical Simulation of Turbulent Air Pollution Dispersion in a Typical Mountainous Urban Valley. 4th International Conference on Computer Aided Design and Manufacturing, CADAM 2006.

[4] Mašić, A. (2015).Unmanned Aerial Vehicle as Data Acquisition System. Journal of Trends in the Development of Machinery and Associated Technology. Vol. 19, No. 1, 2015, ISSN 2303-4009 (online), p.p. 181-184.

[5] Wiesel,W. E. (2010). Spaceflight dynamics, Aphelion Press, ISBN: 978-1-4528795-9-8, Beavercreek, Ohio, USA.

[6] Etkin, B. \& Reid, L. D. (2010). Dynamics of Flight: Stability and Control, John Wiley \& Sons, ISBN: 9788126528912.

[7] Isidori, A. (1999). Nonlinear Control Systems II (Communications and Control Engineering), Springer-Verlag, ISBN: 978-1447111603, London, GB.

[8] Sira-Ramirez, H. \& Agrawal, S.K. (2004). Differentially flat systems, Marcel Dekker, ISBN: 978-0824754709, New York, USA.

[9] Kril, S.; Fedoryshyn, R.; Kril, O. \& Pistun, Y. (2014). Investigation of Functional Diagrams of Step PID Controllers for Electric Actuators. 25th DAAAM International Symposium on Intelligent Manufacturing and Automation, DAAAM 2014

[10] Pillay, N. \& Govender, P. (2013). A Data Driven Approach to Performance Assessment of PID Controllers for Setpoint Tracking. 24th DAAAM International Symposium on Intelligent Manufacturing and Automation, 2013.

[11] Matusu, R. (2011). Regions of Stability for PID Controllers. Annals of DAAAM for 2011 \& Proceedings of the 22nd International DAAAM Symposium, Volume 22, No. 1, ISSN 1726-9679 ISBN 978-3-901509-83-4, Editor B. Katalinic, Published by DAAAM International, Vienna, Austria, EU, 2011.

[12] Vasca, F. \& Ianelli, L. (2012). Dynamics and Control of Switched Electronic Systems. Springer-Verlag, ISBN: 9781447128847, London, GB.

[13] Kushner, D. (2011). The Making of Arduino. IEEE Spectrum.

[14] Dolinay, J.; Dostalek, P. \& Vasek, V. (2010). Simple and Cheap Microcontroller Kit for Students, Annals of DAAAM for 2010 \& Proceedings of the 21st International DAAAM Symposium, 20-23rd October 2010, Zadar, Croatia, ISSN 1726-9679, ISBN 978-3-901509-73-5, Katalinic, B. (Ed.), pp. 0517-0518, Published by DAAAM International Vienna.

[15] https://www.sparkfun.com/datasheets/Sensors/Temperature/DHT22.pdf (2016). Digital-output relative humidity \& temperature sensor/module, Accessed on: 2016-10-17.

[16] https://www.sparkfun.com/datasheets/Components/General/BST-BMP085-DS000-05.pdf (2016). BMP085 Digital Pressure Sensor Data Sheet, Accessed on: 2016-10-17. 